INVESTIGACIÓN/RESEARCH

\title{
EL MAXIMATO: MITO Y REALIDAD DEL PODER POLÍTICO EN MÉXICO
}

Angélica Mendieta Ramírez1: Benemérita Universidad Autónoma de Puebla. México. angelicamendietaramirez@yahoo.com.mx

\section{RESUMEN}

El presente trabajo propone un modelo de análisis histórico-político que permite identificar qué tan "máximo" será la influencia de un ex mandatario sobre un gobernante en turno. A partir de la crítica a la tradición que ha mitificado al "Maximato" como una época de ejercicio del poder omnímodo de Plutarco Elías Calles sobre tres Presidentes de la República, se revisa la estructura de los gabinetes presidenciales, qué lugares desde donde se articulan las decisiones que definen a un gobierno y se establecen los ejes estratégicos del ejercicio del poder en un régimen. Por otra parte, se definen las funciones que llega a tomar el Presidente en turno, en contradicción con los intereses y fuerzas que representa un ex mandatario. La pregunta central es: ¿qué tanto el Maximato es más un mito que una realidad del poder político en México?

PALABRAS CLAVE: Poder - Poder político - Presidencialismo - Ideología Maximato.

\footnotetext{
${ }^{1}$ Autor correspondiente:

Angélica Mendieta Ramírez: Profesora-Investigadora de la Facultad de Ciencias de la Comunicación de la Benemérita Universidad Autónoma de Puebla. México.

Correo: angelicamendietaramirez@yahoo.com.mx
} 


\title{
THE MAXIMATO: MYTH AND REALITY OF THE POLITICAL POWER IN MEXICO
}

\begin{abstract}
A model of political analysis that identifies what is proposed as "Max" will be the influence of a former President on a ruler in turn. From the critique of tradition which has mythified the "Maximato" as a time of realization of the comprehensive power of Plutarco Elías Calles on three Presidents of the Republic, the structure of presidential cabinets, to places from where articulate decisions that define a Government and establishing the strategic axes of the exercise of power in a regime is reviewed. On the other hand, are defined functions that arrive to take the Chair in turn, in contradiction with the interests and forces that represents a former President. The central question is: how much the Maximato is more a myth than a reality of political power in Mexico?
\end{abstract}

KEYWORDS: Power - Political Power - Presidentialism - Ideology - Maximato.

\section{INTRODUCCIÓN}

El Maximato como caracterización del periodo histórico que comprende los años de 1929 a 1935, aporta elementos de análisis que permiten comprender los rasgos característicos de la transmisión del poder presidencial en México.

El presente ensayo tiene como objeto central el estudio y análisis del Maximato a partir del cual se establecerán parámetros que nos permitirán identificar y graduar la fuerza política e influencia que ejerció el general Plutarco Elías Calles después de la creación del Partido Nacional Revolucionario (PNR) sobre la política gubernamental. Razón por la que tomaremos en cuenta los acontecimientos y decisiones que se llevaron a cabo durante los gobiernos de Emilio Portes Gil, Pascual Ortiz Rubio y Abelardo L. Rodríguez y el inicio del período de Lázaro Cárdenas, como presidentes de México.

\section{METODOLOGÍA}

La hipótesis central de esta investigación es: La máxima autoridad no era Calles, sino que ésta se encontraba compartida con el Presidente en turno, porque el poder que él ejercía a través del PNR tenía una influencia moderada, es decir, el Maximato no fue absoluto. Para demostrar esto, tomaremos en cuenta los personajes que integraron los gabinetes de gobierno en este período, y cuáles fueron los factores que influyeron para su designación. A través de estos indicadores trataremos de medir la influencia de Calles sobre las decisiones de los presidentes de 1928 a 1935, para integrar su gabinete. Para lo cual se considera necesario hacer un estudio sobre la formación de los gabinetes de Venustiano Carranza a Lázaro Cárdenas, y a partir de ahí establecer y señalar las características principales de sus colaboradores, que nos confirmará o refutará nuestra hipótesis y determinar si hubo continuidad o ruptura en el gabinete de Lázaro Cárdenas. 


\section{ANÁLISIS Y DISCUSIÓN}

\subsection{Factores de designación de los gabinetes presidenciales: 1916-1924.}

El Maximato es, en la historia política del México contemporáneo, la piedra angular para entender el desarrollo y evolución del sistema político mexicano. Plutarco Elías Calles es el caudillo que quiso unificar, controlar o, en ocasiones reprimir, a la clase política revolucionaria sobre todo cuando el "interés" de su voluntad así lo precisare. Mismo criterio que empleó con la Iglesia Católica cuando la consideró nociva a su voluntad. Éste buscó, a toda costa una vez terminado su período presidencial marcar la pauta de la política nacional en los gobiernos subsecuentes hasta 1935. A este período histórico en que se practicó esta forma peculiar de ejercer el poder tras el trono se le conoció en México como el Maximato. Esta investigación pretende saber hasta qué grado Calles impuso su voluntad a los presidentes inmediatos (Portes Gil, Ortiz Rubio, Abelardo Rodríguez y Lázaro Cárdenas) en la designación de sus gabinetes.

Empezaremos por sostener que para realizar un análisis como el que se pretende, es necesario saber quiénes conformaron los gabinetes e identificar a qué camarilla o sector ideológico-revolucionario o profesional (aquí le llamo factores de designación) al que pertenecían quienes integraron los gabinetes de Venustiano Carranza (fue donde Calles ocupa su primer puesto de gobierno importante) hasta Álvaro Obregón. Posteriormente, se analizarán los períodos de Calles a Lázaro Cárdenas, es decir, de 1924 a 1935, estableciendo de la misma manera y con los mismos criterios las tendencias de los miembros que conformaban sus gabinetes. Estos elementos nos permitirán determinar el grado de influencia real del Maximato en referencia a los gobiernos citados y si hubo continuidad o ruptura del Maximato con el inicio del cardenismo en lo que se refiere a la conformación de los gobiernos posrevolucionarios inmediatos. El presente ensayo tiene como tarea el reflexionar el Maximato, pero no para enfrascarlo como se ha hecho a través de la historia de México, sino más bien para conocer hasta qué punto fue absoluto o moderado ese Maximato.

Partiendo de nuestro primer foco de estudio, a continuación desarrollaremos brevemente algunos de los sucesos ocurridos durante el período de 1916 a 1924, a través de los tres factores de designación que hemos considerado los más importantes porque por medio de ellos podremos explicar la influencia de éstos en la designación de los tres gabinetes que se formaron en estos años, los cuales estarán divididos en tres ramas: 1) Afiliación ideológica, en la que se tomarán en cuenta sus inclinaciones con el maderismo, el huertismo, villismo, zapatismo, carrancismo, obregonismo y con el constitucionalismo; 2) extracción social, referente a su profesión; y 3) experiencia política, que se refiere a los puestos públicos, es decir, a su práctica política gubernamental.

De los miembros que llegaron a integrar cada uno de los gabinetes de Carranza, Huerta y Obregón, señalaremos en términos absolutos las principales inclinaciones de sus integrantes, a fin de determinar su ideología política (Ver Cuadro 1). 
Cuadro 1. Factores de designación: 1916-1924

\begin{tabular}{|c|c|c|c|}
\hline CARACTERÍSTICAS & $\begin{array}{c}\text { VENUSTIAN } \\
\text { O CARRANZA } \\
(1916-1920)\end{array}$ & $\begin{array}{c}\text { ADOLFO DE } \\
\text { LA HUERTA } \\
\text { (MAY1920- } \\
\text { NOV1920) }\end{array}$ & $\begin{array}{c}\text { ALVARO } \\
\text { OBREGÓN } \\
(\mathbf{1 9 2 0 - 1 9 2 4 )}\end{array}$ \\
\hline Miembros del Gabinete & 37 & 11 & 17 \\
\hline $\begin{array}{l}\text { 1) Afiliación Ideológica: } \\
\text { Maderistas }\end{array}$ & 24 & 9 & 10 \\
\hline Huertistas & 10 & 8 & 8 \\
\hline Villistas & 31 & 2 & $\mathbf{1}$ \\
\hline Zapatistas & 31 & 2 & 1 \\
\hline Carrancistas & 26 & 2 & 2 \\
\hline Obregonistas & 5 & 3 & 8 \\
\hline Constitucionalismo & 32 & 8 & 11 \\
\hline Apoyo-anticlericales & 8 & 2 & 1 \\
\hline $\begin{array}{l}\text { 2)Extracción Social: } \\
\text { Profesionista }\end{array}$ & 31 & 6 & 14 \\
\hline Militar & 16 & 6 & 8 \\
\hline $\begin{array}{l}\text { 3)Experiencia Política: Práctica } \\
\text { Política }\end{array}$ & 29 & 6 & 12 \\
\hline Miembro del ant. Gab. & - & 3 & 7 \\
\hline
\end{tabular}

Fuente: Elaboración propia con los datos obtenidos de la Enciclopedia de México, Tomos I-XII, México, 1978 y Tzvi Medín, El minimato presidencial, México, 1996.

En el período de Venustiano Carranza (1916-1920), la mayoría de sus colaboradores que integraban su gabinete, también estaban afiliados al maderismo, es decir, aspiraban a una democracia dirigida hacia la libertad individual, el gobierno por las instituciones y no por el poder absoluto de una persona. Formando parte de su gabinete provisional como secretario de Guerra y Marina. Las principales características del gabinete de Carranza fueron: el 64\% estuvieron afiliados al maderismo, es decir, su misma tendencia y por consiguiente en contra de Victoriano Huerta, casi la totalidad de ellos apoyaban las ideas constitucionalistas, eran profesionistas y habían ocupado puestos políticos; el $71.4 \%$ se declaraban libremente callistas. Un poco más del $40 \%$ eran militares y solo una mínima parte apoyaba las ideas anticlericales (Cuadro 1). Esto nos indica que la mayoría de su gabinete apoyaba sus ideas basadas principalmente en la formación de un Estado fuerte, la destrucción total del régimen dictatorial al igual que el maderismo, la defensa de la propiedad privada y la conformación de una estructura legal independiente de los intereses particulares que protegiera y fomentara las libertades públicas. Todo esto con el fin de aplicar en nuestro país los principios del liberalismo, lo cual era necesario para impulsar el desarrollo capitalista de la época. 
Por otro lado, los constitucionalistas "pronto se dieron cuenta de la importancia que tenía la participación de las masas populares quienes por su cuenta ya realizaban sus propias luchas principalmente los campesinos y los obreros (Loyola, 1988, p.71)" De ellos tomaron los reclamos tendientes a lograr una reforma agraria y mejores condiciones de vida.

En este período eran apoyadas casi de manera absoluta las ideas villistas y zapatistas, por lo tanto, pocos integrantes estaban en contra de ellos; aunque el villismo no presentó un programa de carácter nacional y su influencia se limitó al territorio del norte convirtiéndose en el defensor de la justicia. Por su parte, los objetivos de los zapatistas eran colectivistas, resaltando la importancia de los pueblos como base de la organización campesina. Sin embargo, tampoco este último movimiento ofreció alternativas de solución a los problemas de todo el campesinado nacional, sino que se concentró principalmente en una sola región, la de Morelos (estado natal de Emiliano Zapata).

"La muerte de Carranza simbolizó, sin lugar a dudas, la necesidad y la urgencia de la búsqueda de ese mecanismo político que permitiera que la revolución se encauzara positivamente, sacudiéndose de encima las guerras fratricidas que constituían su rasgo más característico. Adolfo de la Huerta, Francisco Serrano, Arnulfo Gómez, la reelección de Álvaro Obregón, Plutarco Elías Calles y el maximato son nombres, hechos y destinos trágicos que constituyen hitos dramáticos y trascendentes en la búsqueda de ese mecanismo político salvador (Medin, 1996, p.13)."

Después de la muerte de Carranza, Adolfo de la Huerta (May 1920-Jun 1920) de tendencia maderista y de filiación carrancista cooperó en la decena trágica. Ocupó su lugar interinamente; estaba también en contra del general Victoriano Huerta que fue también obregonista. Su objetivo principal como presidente fue lograr la paz conciliando los intereses de las distintas facciones revolucionarias así como convocar a elecciones presidenciales.

Durante este período observamos que su gabinete estuvo conformado por más maderistas que en el período de Carranza por más de 20 puntos porcentuales (Cuadro 1); sus integrantes al contrario de éste fueron casi en un30 por ciento no profesionistas y más militares y con menos práctica política respecto al anterior gobierno, otro factor importante es que la tendencia carrancista es casi nula. También se observa que aproximadamente una tercera parte de sus integrantes había formado parte del gabinete de Carranza. Lo que lleva a precisar que el maderismo estaba más incrustado en la conformación del gobierno delahuertista que el elemento carrancista.

Por último en el periodo de Álvaro Obregón (1920-1924), éste "Buscó el equilibrio, la conciliación de las clases sociales entre empresarios y trabajadores, aplicó una política populista con el fin de ayudar a los desposeídos sin dañar la propiedad privada (proceso de inclusión) (Loyola, 1988, p.74)". Practicó esta forma de gobernar para lograr mantenerse en el poder a pesar de las constantes rebeliones alzadas en protesta a su régimen que fueron más peligrosas a medida que terminaba su período de gobierno. Una de ellas fue organizada por el expresidente interino Adolfo de la Huerta 
(fue uno de los colaboradores dentro de su gabinete), disgustado porque Obregón apoyó la candidatura de Plutarco Elías Calles para las próximas elecciones presidenciales. La rebelión delahuertista duró cuatro meses aproximadamente pero fue derrotada, a pesar del apoyo que tuvo en varias partes del país, por las fuerzas del gobierno, dirigidas por el propio presidente Obregón.

Este período varía un poco más en comparación con los anteriores regímenes, porque las tendencias de sus integrantes son, por un lado la mayoría maderistas contra el huertismo, y existía igual que en el gobierno anterior una mínima inclinación carrancista que casi desaparece, y por el otro, existe nuevamente lo mismo que en el gabinete de Carranza, integrantes profesionistas y con una amplia participación política gubernamental, aumentando además en comparación al gabinete de Adolfo de la Huerta, un $40 \%$ de sus componentes había pertenecido a éste (Ver Cuadro 1).

Ahora bien, habiendo descrito de manera concreta los principales factores que intervinieron en la designación para conformar sus gabinetes se observaron muestras de continuidad en este período, sobre todo en el empleo de elementos de reingambre maderista en la conformación de estos primeros tres gobiernos analizados, salvo algunas excepciones, con la integración de elementos Carrancistas y delahuertistas, según se aprecia en el Cuadro 1.

\subsection{Factores de designación de los gabinetes presidenciales: 1924-1935}

A continuación empleando los mismos criterios que en esta primera parte, se analizarán los factores de designación del siguiente período conocido como el Maximato. De los miembros que llegaron a integrar cada uno de los gabinetes: Plutarco Elías Calles, Portes Gil, Ortiz Rubio, Abelardo L. Rodríguez y Lázaro Cárdenas: Primer Gabinete (13), Segundo Gabinete (11). Señalaremos en términos absolutos las principales inclinaciones de sus integrantes, a fin de determinar su ideología política en esos tiempos (Ver Cuadro 2).

Cuadro 2. Factores de designación: 1924-1935

\begin{tabular}{|l|c|c|c|c|cc|}
\hline CARACTERÍsTICAS & $\begin{array}{c}\text { PLUTARC } \\
\text { O ELÍAS } \\
\text { CALLES } \\
(1924-1928)\end{array}$ & $\begin{array}{c}\text { EMILIO } \\
\text { PORTES } \\
\text { GIL } \\
(1928- \\
1930)\end{array}$ & $\begin{array}{c}\text { PASCUAL } \\
\text { ORTIZ } \\
\text { RUBIO } \\
(1930-1932)\end{array}$ & $\begin{array}{l}\text { ABELARDO } \\
\text { L. } \\
\text { RODRÍGUEZ } \\
(19321934)\end{array}$ & $\begin{array}{l}\text { LÁZARO } \\
\text { CÁRDENAS (1934- } \\
\text { 1940). Gab. } \\
\text { Gab. }\end{array}$ & $2^{\circ}$. \\
\hline $\begin{array}{l}\text { Miembros del } \\
\text { Gab. }\end{array}$ & 16 & 12 & 34 & 19 & 18 & 20 \\
\hline $\begin{array}{l}\text { 1) Afiliación } \\
\text { Ideológica: } \\
\text { Maderistas }\end{array}$ & 3 & 5 & 9 & 7 & 6 & 8 \\
\hline Huertistas & 13 & 9 & 29 & 15 & 15 & 15 \\
\hline Villistas & 14 & - & 26 & 15 & 14 & - \\
\hline Zapatistas & 13 & - & 26 & 13 & 14 & - \\
\hline Carrancistas & 1 & - & - & - & 1 & 10 \\
\hline
\end{tabular}




\begin{tabular}{|c|c|c|c|c|c|c|}
\hline Obregonistas & 10 & 3 & 14 & 10 & 10 & - \\
\hline Callistas & 6 & 8 & 14 & 9 & 10 & 10 \\
\hline $\begin{array}{l}\text { Apoyo- } \\
\text { anticlericales }\end{array}$ & 1 & 2 & 5 & 4 & - & - \\
\hline $\begin{array}{l}\text { 2)Extracción } \\
\text { Social: } \\
\text { Profesionista }\end{array}$ & 13 & 9 & 24 & 15 & 12 & 15 \\
\hline Militar & 4 & 3 & 15 & 6 & 7 & - \\
\hline $\begin{array}{l}\text { 3)ExperienciaPolít } \\
\text { icar Práctica } \\
\text { Política }\end{array}$ & 16 & 12 & 31 & 18 & 16 & 20 \\
\hline Miembro del PNR & - & 2 & 10 & 1 & 3 & 3 \\
\hline $\begin{array}{l}\text { Miembro del ant. } \\
\text { Gab. }\end{array}$ & 4 & 8 & 14 & 15 & 9 & 3 \\
\hline
\end{tabular}

Fuente: Elaboración propia con los datos obtenidos de la Enciclopedia de México, Tomos I-XII, México, 1978 y Tzvi Medín, El Maximato Presidencial, México, 1996 y Benítez Fernando Lázaro Cárdenas, La Revolución Mexicana, Tomo II y III. México, 1993.

Plutarco Elías Calles (1924-1928) continuó con la política de la reconstrucción nacional bajo las mismas bases que Obregón. Durante su gobierno comenzó a equilibrarse la economía nacional y se inició la institucionalización de la vida política del país. Procedió a reorganizar el ejército con la colaboración del general Joaquín Amaro; enfrentó el problema del caciquismo presente en cada una de las numerosas regiones del país y que se convirtió en un fuerte obstáculo para la integración nacional y se preocupó por la enorme diversidad de partidos políticos que no representaron más que intereses regionales o personales. Durante su gestión se vislumbró la posibilidad de crear un partido que a nivel nacional agrupara a todas esas organizaciones para trabajar bajo una misma causa. Hizo frente al conflicto con la Iglesia Católica surgiendo la guerra cristera. Por último, compartió su poder con Obregón, provocando el descontento del grupo en el gobierno y del congreso.

Este período tiene sus diferencias en relación, a la conformación de los anteriores gobiernos: El porcentaje de afiliados al maderismo en su gabinete es una tercera parte de sus integrantes, es decir, es la más baja en términos porcentuales en relación con los tres períodos ya antes mencionados (Cuadro 1 y 2). El número de profesionistas y su práctica política de este gabinete es mayor que en los tres regímenes anteriores. Esto podría explicarse, diciendo que la mayoría de éstos hombres adquirieron experiencia política en los periodos de 1916 a 1924) (Anexo1). La tendencia carrancista era mínima, en cambio las inclinaciones hacia el obregonismo fueron más marcadas en este gabinete y a diferencia del gabinete de Obregón, en el de Calles sólo una cuarta parte de sus colaboradores habían pertenecido a algún otro gabinete (a partir de Carranza).

En el periodo llamado Maximato, la figura más importante e influyente de la política mexicana fue Plutarco Elías Calles. Durante dicho lapso de tiempo, México tuvo tres presidentes: Emilio Portes Gil fue designado interino debido a la muerte de Obregón, 
Pascual Ortiz Rubio ocupó constitucionalmente la presidencia y Abelardo L. Rodríguez sustituyó interinamente a Ortiz Rubio cuando este renunció dos años después de haber ocupado su puesto.

Emilio Portes Gil (1928-1930) perteneció por primera vez a un gabinete gubernamental en el período precisamente de Plutarco Elías Calles. "Desde un principio Calles fue reconocido como el Jefe Máximo o mejor dicho continuó siendo reconocido como el Jefe Máximo (Medin, 1996, p.53)", sin embargo a pesar de que era callista, no compartía del todo sus ideas con éste, porque durante su período (1929) convino con el clero, sin modificar ninguna ley objetada por la Iglesia, dictar la amnistía general, devolver las casas curales y episcopales y reanudar los cultos de las iglesias. Otra diferencia fue que rechazó el intento de limitar su labor agrarista en el reparto de tierras, produciéndose una diferencia bastante seria, ya que Calles apoyaba la moderación del reparto agrario, siendo esta una de las razones por las que renuncia como presidente provisional. En un solo año Portes Gil logró repartir cerca de dos millones de hectáreas, beneficiando a 126,317 campesinos. Lo importante para Calles durante ese periodo "fue la creación del PNR, bajo su jefatura el evitar la elección de Aarón Sáenz, y lograr la de Ortiz Rubio, el sofocamiento de la prevista y estimulada rebelión militar y el estipular su ascendencia sobre el gobierno interino ya sea directamente o por medio de su influencia en la elección del gabinete. Todos estos objetivos fueron logrados (Medin, 1996, p.54)".

Su gabinete estuvo integrado por 62.5\% de callistas (Cuadro 2), entre ellos Montes de Oca y Puig Casauranc, a pesar de que éstos habían estado en su contra durante su candidatura presidencial. Pero también Portes Gil nombró algunos simpatizadores como Marte R. Gómez, Ezequiel Padilla (aunque eran también de filiación callista). Su principal logro como presidente interino y por lo cual creo que no podemos ser tan radicales como para asegurar que solo reinaba la voluntad de Calles, fue la reducción drástica de la fuerza sindical de la CROM.

Portes Gil aprovechó al máximo su estadía en la presidencia, desarrollando una activa e intensa labor "entre cuyos puntos cumbres cabe señalar el reparto agrario, la solución del problema religioso y el otorgamiento de la autonomía a la Universidad Nacional. Portes Gil intentó crear su propia base de poder a nivel nacional y llevó a cabo en muchos sentidos una labor populista (Medin, 1996, p.59)." Pero fue éste un populismo que se encontró limitado por el llamado "Jefe Máximo" y por el tiempo que duró en su cargo como Presidente Interino de la República.

La presidencia de Pascual Ortiz Rubio (1930-1932) dio comienzo en un ambiente político que se refleja patentemente en el diario oficial El Nacional Revolucionario.

"El general Calles es ahora el centro de la mirada de todos los partidos es el apoyo más serio del nuevo presidente, es la cohesión de todos los grupos revolucionarios, es en una palabra, la garantía de que la revolución no será dividida en muchas piezas y no será presa fácil de los enemigos de ella... Calles está en un lugar en que puede salvar a la revolución amenazada de dividirse, en que puede señalar orientaciones firmes, en que pude contener el desorden y prevenir la anarquía (Medin, 1996, p.74)." 
El Maximato era aceptado por todos y en ese sentido, todos eran callistas. Ninguna de las facciones podía lograr el triunfo sin el apoyo de Calles y a "final de cuentas la posición adoptada por éste decidía todas las contiendas y controversias (Medin, 1996, p.74)". Sin embargo, esto resulta cuestionable, porque si bien es cierto Calles había logrado cierto consenso en la élite política, también es cierto que había generado entre ellos una gran división (CROM, Cristiada, Escobarismo, etc), lo cual nos lleva a percibir que no siempre decidía y resolvía las controversias que se suscitaban.

En la conformación de su gabinete como presidente se encontraban callistas como Portes Gil (gobernación); Luis León (Industria, Comercio y Trabajo), y Manuel Pérez Treviño (Agricultura y Desarrollo), eran representantes de sus grandes aspiraciones personalistas y movían activamente sus poderosos grupos políticos. Manuel Puig Casauranc (Departamento del Distrito Federal), y Luis Montes de Oca (Hacienda) se movían fundamentalmente en forma individual intentando presentarse como callistas puros. Los generales Amaro (Guerra) y Almazán (Comunicaciones y Obras Públicas), eran militares activos desconectados de los que podríamos denominar políticos profesionales y vislumbraban su ascenso político en oposición a éstos y por lo tanto apoyando al presidente frente a los ataques de los líderes del PNR o los portesgilistas. Es decir, a pesar de ello, menos de la mitad de sus colaboradores fueron de tendencia callista $(40 \%)$, con ello se pretende afirmar que hubo mayor influencia de Calles en el período de Emilio Portes Gil que en el de Ortiz Rubio. Durante su gobierno, en materia de cultos, recuperó para la nación el dominio directo sobre 64 casas curales, obispados y seminarios, apoyó la política anticlerical de Calles y Obregón. La profunda división surgida en el Congreso, entre los seguidores de Calles y los que no lo eran, se agudizó a principio de 1930, cuando varios diputados y senadores contrarios al callismo fueron expulsados del PNR recién formado. El conflicto creció debido al nombramiento de Portes Gil como secretario de gobernación, siendo que este era rival del recién ascendido presidente Pascual Ortiz Rubio. La maniobra de Ortiz Rubio consistió "en tratar de neutralizar en lo electoral la fuerza de la Secretaría de Gobernación por medio de su poder en el PNR (Loyola, 1988, p.85)". Calles fue a visitar a Ortiz Rubio y "le rogó que dejara al partido en plena libertad para el manejo de la política (Medin, 1996, p.96)." Si el general Calles, era el "Jefe Máximo" ¿Por qué el presidente se opuso a tal petición?, en este sentido, se hace hincapié que aún con todas las críticas hechas a este presidente, si hubiese aceptado la petición del general Calles, se hubiera evitado un sin fin de problemas con el llamado "Jefe Máximo", lo cual no ocurrió porque él no era la máxima autoridad, y eso es lo que no pudo concebir en su afán por mantener de manera externa el poder gubernamental y tampoco Ortiz Rubio fue el "Jefe Máximo" o la máxima autoridad, sino que más bien fue una coalición de poder entre el callismo (Calles) y el Presidente en turno, por lo tanto, Ortiz Rubio acepto la designación de Calles en el PNR, pero rechazó el Maximato como mecanismo político tal y como se le quiso imponer (no solo a él sino a Portes Gil, Abelardo Rodríguez y Lázaro Cárdenas) y ello trajo como consecuencia rupturas y continuidades en determinados aspectos de la vida política y de gobierno.

La situación se transformó en crisis al acercarse las elecciones para Diputados y Senadores que habrían de renovar el Congreso de la Unión. Dichas elecciones fueron tan violentas que Portes Gil tuvo necesidad de renunciar a la Secretaría de 
Gobernación y a la presidencia del Comité Ejecutivo Nacional del PNR, abandonando el país en octubre de 1930.

Lázaro Cárdenas quedó al frente del partido aplicando una política de reconciliación entre las partes en pugna y de verdadera unión con la política del presidente del país. Lo sustituyó Manuel Pérez Treviño que volvió a convertir al PNR en un instrumento al servicio de Calles.

Para Córdova, Ortiz Rubio fue "una de las figuras más lastimera y patéticas de nuestra historia contemporánea... y que era un inepto en política (Córdova, 1979, p.113)". No estamos de acuerdo con esta apreciación, porque a pesar de los errores que cometió trató en todo momento de hacer valer su autoridad y no supeditarse de manera absoluta al general Calles. A pesar de todas las trabas que le puso en el camino tuvo un gran logro que fue la promulgación de la Ley Federal del Trabajo.

Por otro lado, veamos en primer lugar el porcentaje de gastos presupuestarios federales entre 1929-1934. (Ver Cuadro 3).

Cuadro 3. Gastos presupuestarios federales: 1924-1934

\begin{tabular}{ccccc}
\hline Año & & Económico & Social & Administrativo \\
\hline & 1929 & 23.2 & 12.9 & 63.9 \\
& 1930 & 29.3 & 14.6 & 56.1 \\
1931 & 26.7 & 17.0 & 56.3 \\
& 1932 & 28.4 & 15.8 & 55.8 \\
& 1933 & 20.3 & 15.7 & 64.0 \\
& 1934 & 23.2 & 15.0 & 61.8 \\
\hline
\end{tabular}

Fuente: Medín Tzvi, 1996.

Esto nos indica que durante el periodo de Ortiz Rubio se redujo el gasto administrativo (fuerzas Armada, deuda pública y diferentes dependencias del gobierno), que luego volvió a ascender con Abelardo Rodríguez; y paralelamente se elevó el gasto económico, agricultura y riego, modernización de regiones rurales, crédito agrícola, comunicaciones y obras públicas, etcétera) y también el gasto social (educación, salubridad, asistencia pública, etc.), que volverá a descender luego de la presencia de Ortiz Rubio. Es interesante señalar algunos detalles en estos presupuestos. Así, por ejemplo, los porcentajes dedicados a la agricultura y al riego (Medin, 1996, p.118).

No cabe duda de que el reparto de tierras, como ya lo hemos visto, se vio seriamente reducido durante el periodo ortizrubista (Medin, 1996, p.119), pero el mismo criterio esencialmente economicista que lo llevó a esa política agraria fue también el que lo impulsó a incrementar el crédito agrícola y la irrigación.

El gabinete presidencial de Abelardo Rodríguez (1932-1934) se vio constituido casi por la mitad de callistas; aquí la política anticlerical es de un $23 \%$ del total de sus 
colaboradores. Éste fue un hecho bastante importante, porque Abelardo fue el que pudo ejercer mejor sus funciones en comparación a sus antecesores (Portes Gil y Ortiz Rubio) sus tendencias obregonistas, callistas y anticlericales son más marcadas en este período y de esta menara intentó dar una nueva imagen de la presidencia.

Una vez conformado su gobierno, Rodríguez giró de inmediato una circular a los secretarios de Estado explicitando que la Constitución había establecido un régimen presidencial, siendo el Presidente de la República "el autorizado para nombrar y remover libremente a los secretarios de despacho, al Procurador General de la República, al Jefe del Departamento del Distrito Federal. Y al Procurador General de Justicia, siendo asimismo el Presidente de la República el único responsable directo por los actos de su gobierno (Meyer, 1995, p.101)" Tampoco en este período se le puede llamar "Jefe Máximo" al general Calles porque nuevamente se había topado con limitaciones que obviamente le perjudicaban, ya que ésta circular ponía de manifiesto un derecho y obligación que todo Presidente de la República debía acatar y hacer valer, lo que significaba un debilitamiento del poder que ejercía el general Calles.

Abelardo Rodríguez logró lo que se había propuesto, ya que su obra administrativa resultó más importante que la de su predecesor (Meyer, 1995, p.163): a) "en el aspecto agrario destaca la promulgación del primer Código Agrario el 22 de marzo de 1934". A esta etapa de institucionalización correspondió un aumento en el ritmo del reparto agrario que, sin llegar a recuperar el que tuvo durante el gobierno de Portes Gil, fue muy superior al de la administración de Pascual Ortiz Rubio. b) "en relación al trabajo Rodríguez estableció en septiembre de 1933 un salario mínimo en cada una de las entidades del país, lo que implicó un importante trabajo previo para determinar las condiciones de cada región, una negociación con los representantes del capital y el trabajo y la organización de una maquinaria administrativa que periódicamente revisara el monto de este salario"; c) "en el aspecto financiero, la administración de Rodríguez creó Nacional Financiera y el Banco Nacional Hipotecario Urbano y de Obras públicas; d) en septiembre de 1934, se creó la empresa Petróleos de México (Petromex) mediante aportación oficial, cuya meta sería competir con las grandes empresas extranjeras y surtir el mercado interno en las mejores condiciones".

Estamos de acuerdo con Benítez (1993, p.33) cuando dice que "el poder de Calles ya desde los tiempos de Abelardo Rodríguez era más aparente que real". En primer lugar, como los hechos lo demostraban, no había logrado subordinar al presidente en turno, ni impedir la formación de un "ala izquierda" en las Cámaras, ni mucho menos controlar las nuevas organizaciones de los trabajadores y los campesinos. "El presidente no sería más el pelele de una fuerza política extraña al gobierno (1993, p.37)". Calles dejaba de ser el Jefe Máximo de la Revolución.

La candidatura de Lázaro Cárdenas (1934-1940) a la presidencia planteaba la continuidad del llamado "Maximato" y su política reaccionaria, del mismo modo que esa política que negaba a los intereses populares exigía para su realización la directiva de una oligarquía y la neutralización de las fuerzas populares evitando su participación política (Medin, 1996, p.137)". Solo le bastaron 6 años de participar en la política para llegar a la presidencia de la República. El plan sexenal del cardenismo 
postulaba como principio básico "el del intervencionismo estatal en las relaciones económica y sociales (Córdova, 1979: 448)". Se trataba de reivindicar los principios de la revolución, con los que no estaba de acuerdo Calles. Este Plan se dividía en 10 apartados entre los que destacan: Economía, Trabajo, educación y obras Públicas. Su proyecto se fundaba "en la participación de los trabajadores, en la solución de problemas: políticos, sociales y económicos, pero no cuenta y riesgo de los trabajadores, sino encuadrados en una organización que sirviera de apoyo al gobierno. Pensó que el mejor modo de conservar el poder era poner a las masas del lado del gobierno revolucionario (Córdova, 1979, p.428)."

Comparto la opinión de Córdova (1979) cuando dice que Cárdenas "no agregó nada nuevo, solo aprendió a aplicar los principios de la revolución de manera cabal sin mediaciones oportunistas. Nadie lo había logrado (ni Carranza, Obregón, Calles) Cárdenas no dejó de reiterar su compromiso con los trabajadores del Estado y con el ejército (Córdova, 1979, p.437)". Este mecanismo para la estabilidad y el desarrollo de México no fue el producto del genio de algún mexicano, sino la consecuencia de un desarrollo histórico, durante el cual los protagonistas principales intentaron dar diferentes respuestas en función de la realidad mexicana, como por ejemplo la necesidad de la legalidad constitucional, "el sufragio efectivo no reelección” y "tierra y libertad".

Al inicio del gobierno encabezado por Cárdenas parecía augurar que el Maximato continuaría siendo la realidad dominante de la política mexicana. El gobierno se integró con la participación de prominentes callistas, como el mismo hijo de Calles, Rodolfo, en la Secretaría de Comunicaciones; Tomás Garrido Canabal pasó a ocupar la Secretaría de Agricultura; Juan de Dios Bojórquez detentaba la Secretaría de Gobernación.

Cárdenas consideraba a Calles como el Jefe de la Revolución, pero ello no implicaba que como presidente de la República aceptara necesariamente el mecanismo político del Maximato y menos aún la política socioeconómica del callismo.

El período de Cárdenas no es una continuación del "Maximato", ya que en lo político Cárdenas intentó marginar desde un principio a sus contrarios. Cárdenas dio su apoyo masivo al movimiento obrero y asimismo aspiró a llevar a cabo una verdadera revolución agraria incrementando decisivamente el reparto de tierras. Forzó la renuncia de los integrantes de su gabinete presidencial y el 17 de junio integró su nuevo gabinete, esta vez "purificado" de los callistas. El nuevo gobierno era exclusivamente de cardenistas.

Terminada la tarea de eliminar a los callistas del PNR, el Congreso y las gubernaturas de los estados, Portes Gil mismo dejó la presidencia del PNR, “desgastado por las muchas animadversiones y por acusación de no estar poniendo el partido enteramente al servicio del presidente sino de sí mismo (Aguilar, 1993, p.153)". Cárdenas lo sustituyó con un hombre de su total confianza, Silvano Barba González. A este control presidencial del partido, del Congreso y las gubernaturas, debe añadirse el de otra pieza clave: el ejército. En la reestructuración del gabinete, la Secretaría de Guerra 
quedó al mando de un hombre muy leal a Cárdenas, el general Andrés Figueroa, "quien moriría antes de terminar el sexenio pero no antes de quitar de en medio a los callistas abiertos, Joaquín Amaro de la dirección de Educación Militar, Manuel Medinaveitia, Pedro J. Almada de la jefatura de operaciones de Veracruz, etc. (Aguilar, 1993, p.153)".

Finalmente el 10 de abril Calles y sus acompañantes abandonaron el país. El "Maximato" no había logrado funcionar como mecanismo político llegando a su fin y desapareciendo el líder del callismo. Prueba clara de que éste periodo había llegado a su fin lo representaba el escaso control sobre movimientos huelguísticos (más bien tolerancia) del gobierno de Cárdenas. Esta tendencia se había notado desde 1932, Esto es la imposición de políticas callistas de represión a estos movimientos (en los gobiernos del Maximato) se debilitaba. (Ver Cuadro 4).

\section{Cuadro 4. Número de huelgas: 1929-1935}

\begin{tabular}{cc}
\hline Año & Número de Huelgas \\
\hline 1929 & 14 \\
1930 & 15 \\
1931 & 11 \\
1932 & 56 \\
1933 & 13 \\
1934 & 202 \\
1935 & 642 \\
\hline
\end{tabular}

Fuente: James W. Vilkie y Edna Manzande Wilkie

\section{CONCLUSIONES}

El Maximato no era otra cosa que la autoridad suprema de Calles, la cual era aceptada unánimemente. El instrumento fundamental para ello fue el PNR, que fue creado como jefatura absoluta del general Calles y por medio del cual se dominaría al Congreso de la Unión, y en cuyo nombre podría Calles imponer la constitución de los gabinetes presidenciales.

El período de Emilio Portes Gil, Ortiz Rubio y Abelardo Rodríguez no fue un Maximato absoluto de poder, sino un callismo o un "Maximato moderado" el cual lo podemos definir como la coalición de dos poderes: el de Calles y el Presidente en turno, con sus derechos, obligaciones, pero sobre todo con sus limitaciones puestas entre sí, y de su proyecto político. Compartieron el poder, pero ninguno logró hacer declinar el poder del otro de manera total o absoluta.

Calles no fue el máximo jefe durante el periodo de 1928-1934, ni mucho menos del período de 1934-1940, sin embargo aunque su influencia no fue total y absoluta, también consideramos que fue legitimado, es decir, consensado por la mayoría de la clase política de éstos años (1928-1934), ganado por esa gran experiencia política y electoral, por lo tanto, lo único que hizo fue aprovechar lo ya antes planteado como 
por ejemplo la idea de crear un partido de Estado fue una propuesta de Limantour en 1903, en la época de la dictadura, y que se fue desarrollando con el paso del tiempo hasta concretarse con la creación del PNR en 1929 por Calles.

Tanto en el gabinete de Emilio Portes Gil hasta el de Abelardo L. Rodríguez hay una misma tendencia que la ocurrida de Carranza a Calles hacía un maderismo bastante pronunciado, a pesar del tiempo ya transcurrido. Lo mismo ocurre con el nivel de estudios de sus miembros casi en la totalidad de ellos son profesionistas y que han ocupado puestos políticos, ya sea como diputados (locales o federales), senadores, gobernantes de sus estados natales principalmente. El apoyo a prácticas anticlericales son muy mínimas y por lo tanto contrarias a las de Calles.

Lo que sí fue muy marcado es que la mayoría de los integrantes del gabinete carrancista fueron claves determinantes para la formación de los sucesivos gabinetes, es decir, no hubo mayores cambios tal y como lo muestran los cuadros 1 y 2 . Ello significa que Calles no fue un genio, sólo supo aprovechar lo que las diversas fuerzas políticas le adjudicaron y supo negociar hasta 1934 su poder, aunque ya en éste año se encontraba debilitado. Pero como desde que existe el presidencialismo, existe también la forma personal de gobernar y esta sí fue una continuidad heredada no sólo por Calles, sino por todos los presidentes en mayor o menor grado. Lo que sí heredó directamente Lázaro Cárdenas de Calles fue su gabinete el cual estaba formado por hombres fieles a éste, pero ¿cómo no habría de aceptarlos si fueron parte importante para su designación como Presidente? Además fungieron como la única forma de acceder al poder de manera pacífica, siendo esta una estrategia política que después supo remediar al reorganizar su gabinete, esta vez pendiente de que no existiera ya más la influencia callista dentro de su gobierno.

\section{BIBLIOGRAFÍA}

Águilar, C. H. y Meyer, L. (1993). A la sombra de la Revolución Mexicana. Cal y Arena, México.

Álvarez, J. R. (2000). Enciclopedia de México, S.A. Tomo I al XII, 5a . Edición, México.

Antología (1913-1936) (1988). Pensamiento Político y Social. Plutarco Elías Calles. 1. Edición, Fondo de Cultura Económica, México.

Benítez, F. (1993). Lázaro Cárdenas y la Revolución Mexicana. El caudillismo Tomo II y el Cardenismo Tomo III, F.C.E. México.

Bernal Talavares, L.; Lombardo, V. y Alemán, M. (1994). Una bifurcación de la Revolución Mexicana. Centro de Estudios de Investigación para el Desarrollo Social, México.

Colmenares, I.; Gallo, M.; González, F. y Hernández, L. (Coords) (1997). Cien años de Lucha en México. Tomo II, Ediciones Quinto Sol, México. 
Córdova, A. (1979). La revolución en crisis. La aventura del Maximato. 2a . Edición, Diana, México.

Diccionario Porrúa (1986). Historia, Biografía y Geografía de México. Porrúa, México.

Manlio, F. Y Murillo, S. (1979). La reforma Politica Mexicana y el Sistema pluripartidista. $2^{a}$ Edición, Diana, México.

Loyola, R. (1988). La crisis Obregón-Calles y el Estado Mexicano. 5a. Edición, Siglo XXI, México.

Martínez Assad, C. (Coord.) (1988). Sociedad y Politica en México. Estadísticas, Caciques y Caudillos. $1^{\text {a }}$ Edición, UNAM, México.

Martínez, F. (2008): “Comunicación política en tiempos de crisis", en la Revista SEECI, no. 15 , Madrid.

Medin, T. (1996). El minimato presidencial: historia politica del maximato 1928-1935. Ediciones Era, México.

Meyer, L.; Segovia, R. y Lajous, A. (1995). Historia de la Revolución Mexicana 1928-1934. Los inicios de la institucionalización. $2^{\mathrm{a}}$ Reimpresión, Tomo XII, COLMEX. México.

Meyer, J.; Krauze, E. y Reyes, C. (1981). Historia de la Revolución Mexicana: 1924-1928. Estado y Sociedad con Calles. $1^{\mathrm{a}}$ reimpresión, COLMEX, México.

Moreno, D. (1977). Los Partidos Políticos del México Contemporáneo (1916-1977). $6^{\mathrm{a}}$ Edición, B. COSTA-AMIC EDITOR, México.

W. F. Dulles, J. (1982). Ayer en México, una crónica de la Revolución (1919-1936). $1^{\mathrm{a}}$ Reimpresión, F.C.E., México.

W. Wilkie, J. y Monzón, E. (1969). México visto en el siglo XX. $1^{\text {a }}$ Edición, Instituto Mexicano de Investigaciones Económicas. México. 


\section{Angélica Mendieta Ramírez}

Doctora en sociología, posdoctorado en educación, Maestra en Ciencias Políticas, en 2004 realizó una estancia en la Universidad de Harvard. Pertenece al Sistema Nacional de Investigadores (SNI-Nivel-I). Miembro del Cuerpo Académico de "Comunicación Política", Conferencista Nacional e Internacional. Es autora de los conceptos: Electopartidismo y el bucle de la comunicación política. Es autora, coautora y coordinadora de diversos libros sobre política y educación. Es Profesora-Investigadora de Tiempo Completo de la Facultad de Ciencias de la Comunicación de la BUAP. 